\title{
Hepatotoxicity of Halogenated Inhalational Anesthetics
}

\author{
Saeid Safari ${ }^{1}$; Mahsa Motavaf ${ }^{2,3}$; Seyed Alireza Seyed Siamdoust ${ }^{1}$; Seyed Moayed Alavian ${ }^{3,4, *}$ \\ ${ }^{1}$ Department of Anesthesiology and Pain Medicine, Iran University of Medical Sciences, Tehran, IR Iran \\ ${ }^{2}$ Department of Genetics, Faculty of Biological Sciences, Tarbiat Modares University, Tehran, IR Iran \\ 3 Department of Molecular Hepatology, Middle East Liver Disease Center, Tehran, IR Iran \\ 4 Baqiyatallah Research Center for Gastroenterology and Liver Diseases, Baqiyatallah University of Medical Sciences, Tehran, IR Iran \\ ${ }^{*}$ Corresponding Author: Seyed Moayed Alavian, Baqiyatallah Research Center for Gastroenterology and Liver Diseases, Baqiyatallah University of Medical Sciences and Tehran Hepa- \\ titis Center, Tehran, IR Iran. Tel: +98-2188945186, Fax:+98-2188945188, E-mail: alavian@thc.ir
}

Received: May 11, 2014; Revised: August 18, 2014; Accepted: July 31, 2014

\begin{abstract}
Context: Halogenated inhalational anesthetics are currently the most common drugs used for the induction and maintenance of general anesthesia. Postoperative hepatic injury has been reported after exposure to these agents. Based on much evidence, mechanism of liver toxicity is more likely to be immunoallergic. The objective of this review study was to assess available studies on hepatotoxicity of these anesthetics.

Evidence Acquisition: We searched PubMed, Google Scholar, Scopus, Index Copernicus, EBSCO and the Cochrane Database using the following keywords: "inhalational Anesthetics" and "liver injury"; "inhalational anesthetics" and "hepatotoxicity"; "volatile anesthetics" and "liver injury"; "volatile anesthetics" and hepatotoxicity for the period of 1966 to 2013. Fifty two studies were included in this work.

Results: All halogenated inhalational anesthetics are associated with liver injury. Halothane, enflurane, isoflurane and desflurane are metabolized through the metabolic pathway involving cytochrome P-4502E1(CYP2E1)and produce trifluoroacetylated components; some of which may be immunogenic. The severity of hepatotoxicity is associated with the degree by which they undergo hepatic metabolism by this cytochrome. However, liver toxicity is highly unlikely from sevoflurane as is not metabolized to trifluoroacetyl compounds.

Conclusions: Hepatotoxicity of halogenated inhalational anesthetics has been well documented in available literature. Halothaneinduced liver injury was extensively acknowledged; however, the next generation halogenated anesthetics have different molecular structures and associated with less hepatotoxicity. Although anesthesia-induced hepatitis is not a common occurrence, we must consider the association between this disorder and the use of halogenated anesthetics.
\end{abstract}

Keywords:Anesthesiology; Liver Injury Drug-Induced; Inhalation Anesthesia; Halothane; Sevoflurane

\section{Context}

Halogenated inhalational anesthetics are the most commonly used agents for induction and maintenance of general anesthesia. The choice of anesthetic depends on many factors including ease of administration, cost, availability and permissibility of their effects. For more than 50 years, halogenated inhalational anesthetics have been documented to be associated with liver injury. Chloroform the original halogenated anesthetic abandoned for a long period is indicated to be hepatotoxic by different studies $(1,2)$. Halothane, introduced in 1950 s as a safer alternative for chloroform, causes a well-documented syndrome of acute hepatotoxicity as well. Enflurane and isoflurane are two halogenated anesthetics that followed halothane. These agents are also shown to cause similar injury, but less than halothane (3). Fortunately, fewer cases of hepatotoxicity have been reported for the newest agents, desflurane and sevoflurane (4). Most hypotheses on the mechanism of halogenated anesthetics-induced hepatic injury are based on the production of metabolites causing immunoallergic reaction in patients. All of these anesthetics undergo biotransformation, primarily involving cytochrome P-450 2E1 (CYP 2E1) (5). The likelihood that each halogenated inhalational anesthetic causes liver injury correlates with the extent to which it is metabolized by this cytochrome (20\% to $30 \%$ for halothane, $2 \%$ for enflurane, $1 \%$ for sevoflurane, and $0.2 \%$ or less for isoflurane and desflurane) and the metabolic products (5). In this study, we aimed to review available literature documenting the mechanism and extent by which these agents cause liver injuries.

\section{Evidence Acquisition}

The objective of this study was to evaluate hepatotoxicity of available halogenated inhalational anesthetics. A review of the available literature was performed in April 2014. Our aim was to find all previous works describing hepatotoxic effects of these agents. Electronic search was performed by searching several databases (PubMed, Google Scholar, Scopus, Index Copernicus, EBSCO and the Cochrane Database) using the keywords including "inhalational anesthetics" and "liver injury"; "inhalational anesthetics" and "hepatotoxicity"; "volatile anesthetics"

Copyright (C) 2014, Iranian Red Crescent Medical Journal; Published by Kowsar. This is an open-access article distributed under the terms of the Creative Commons Attribution-NonCommercial 4.0 International License (http://creativecommons.org/licenses/by-nc/4.0/) which permits copy and redistribute the material just in noncommercial usages, provided the original work is properly cited. 
and "liver injury"; "volatile anesthetics" and "hepatotoxicity"; for the period of 1966 to 2013. In addition, we examined cited references in these studies with the same keywords. All randomized clinical trials, case series, case report and meta-analysis studies with the above mentioned contents were included in review process. Totally, 247 articles were found in primary search, from which 52 articles were eligible and enrolled in this study.

\section{Results}

\subsection{Halothane Hepatotoxicity}

Halothane is a classic form of halogenated anesthetics, which was introduced in 1956 and rapidly became the most commonly used agent for general anesthesia. Within a few years of its introduction, cases of halothaneinduced liver injuries were reported. In 1969, the National Institutes of Health (NIH) organized an epidemiological study on 250000 cases of halothane administration, which revealed an incidence of fatal hepatic necrosis of about 1 in 35000 individuals (6-8). Concerns about its hepatotoxicity eliminated the use of this anesthetic for adults in the United States and many other countries. Two types of postoperative liver injuries have been reported to be associated with halothane administration. Twenty percent of patients receiving halothane anesthesia show a mild injury characterized by nausea, lethargy and fever. Two clinically detectable factors are assumed to contribute to this type of hepatic injury. The first is a transient elevation of liver enzymes, alanine aminotransferase (ALT) and aspartate aminotransferase (AST), which remain elevated for one to two weeks following halothane exposure and resolve without treatment (9). The second is hepatic lesions due to intracellular degradation of halothane following local hypoxia. Halothane associated hypoxia is indicated to be due to alteration in the hepatic oxygen demand and supply relationship $(10,11)$. Mild hepatic injury appears to result from direct toxic effect of halothane on hepatic cells; however, evidence of immune activation is lacking in this type. The other form of liver damage after halothane exposure is severe acute hepatitis with histological findings of massive hepatic necrosis. This form is dose-independent and rare, occurring in approximately 1/15000 cases after initial exposure, but in about 1/1000 cases after repeated exposures (12-15). The severe type of injury is associated with acute elevations in ALT and AST levels ( 5 to 50 fold) and onset of jaundice within 2 to 14 days of halothane administration. There is strong evidence that the severe type of liver injury is mediated by the patient's own immune system. Approximately 60\% to $80 \%$ of inhaled halothane is eliminated unchanged through the lungs, but about $20 \%$ of it undergoes metabolism either in an oxidative (by CYP2E1 and CYP2A6) or reductive (by cytochrome CYP2A6 and CYP3A4) pathways. Halothane oxidation leads to production of trifluoroacetic acid (TFA), which acts on hepatocyte proteins to produce trifluoroacetylated components. Some of these products showed to be immunogenic and induce patient's immune responses. It is indicated that serum of patients with a clinical diagnosis of halothane-induced hepatitis contains circulating immunoglobulin $G(\operatorname{IgG})$, reacting with liver microsomal trifluoroacetylated proteins (16). Repeated halothane exposure stimulates the immune response, increasing the incidence of hepatitis, fever, rash, arthralgia, and peripheral eosinophilia (17, 18). Hepatic injury due to immune response is severe and even sometimes fatal (19). On the other hand, reductive pathways of halothane metabolism produce free radicals that can act as reactive metabolites causing minor injury. Different risk factors have been suggested to increase the incidence of halothane-induced hepatotoxicity. This injury tends to be more severe in persons older than 40 years as they account for $80 \%$ of cases. Two thirds of reported cases occurred in women. Repeated exposure to halothane (especially within a few weeks or months) is documented in as many as $90 \%$ of cases. Obesity is another risk factor, possibly because of accumulation of halothane in adipose tissue. Induction of CYP2E1 by phenobarbital, alcohol, and isoniazid are all risk factors for halothane hepatitis (20-22). However, halothane is no longer used in many developed countries but continues to be used in some developing countries.

\subsection{Hepatotoxicity of Other Halogenated Inhala- tional Anesthetics}

After halothane, other halogenated anesthetics, including enflurane (1972), isoflurane (1979), desflurane (1993) and sevoflurane (1995) have been introduced. Compared to halothane, these agents have the advantage of fewer metabolisms by the CYP2E1 system, which suggests less adverse effects on liver, following their administration $(23,24)$.

\subsubsection{Enflurane Hepatotoxicity}

Enflurane is a widely used halogenated inhalational anesthetic. As it has a slow onset of action, it is used largely to maintain anesthesia after induction with other agents. Enflurane became available in 1972 and is still in use, although less widely than other more modern halogenated agents. Approximately $2 \%$ of enflurane undergoes hepatic metabolism compared to $20-30 \%$ of halothane. Clinically apparent, very rare cases of severe hepatic injury from enflurane have been reported. Like halothane, enflurane is metabolized by the microsomal drug-metabolizing enzyme CYP2E1 to a trifluoroacetylated reactive intermediate, which is capable of binding to multiple intracytoplasmic proteins, forming potentially immunogenic adducts. As the TFA adducts induced antibodies can be detected in patients with enflurane, as well as halothane, it is suggested that the mechanism of enflurane-induced liver injury resembles the mechanism of halothane hepatotoxicity. However, the incidence of enflurane-induced 
hepatotoxicity appears to be less compared to halothane. As with halothane hepatotoxicity, this injury is marked by acute elevations in serum ALT (5- to 50-fold) and appearance of jaundice 2 to 21 days after the operation and anesthesia (25-27).

\subsubsection{Isoflurane}

Isoflurane, an isomer of enflurane, is a widely used anesthetic agent with rapid onset of action and rapid dispersal. It was approved in 1979 and widely accepted as a safer agent with less risk of hepatotoxicity. Since its release by the Food and Drug Administration, controversy has existed about the extent to which isoflurane is capable of producing hepatotoxic effects (3). This agent is suggested to be less hepatotoxic compared to halothane and enflurane; however, there are few case reports, describing fetal hepatotoxicity following single exposure to isoflurane $(3,28,29)$. The mechanism of isoflurane hepatotoxicity is suspected to be similar to that of halothane and associated with production of reactive intermediates.

\subsubsection{Desflurane}

Desflurane is another halogenated anesthetic for induction and/or maintenance of general anesthesia. Similar to previously described agents, desflurane is metabolized to a small but variable extent by the microsomal drug-metabolizing enzyme CYP2E1 to a TFA reactive intermediate, which is capable of binding to multiple intracytoplasmic proteins, forming potentially immunogenic adducts. Occurrence of hepatic injury following desflurane anesthesia was once thought to be rare. However, case reports reporting complications related to the use of this anesthetic continue to be accumulated (30-35). Interestingly, in addition to circulating anti-TFA antibodies $(4,5)$, such as those associated with halothane or isoflurane, recently autoantibodies to CYP2E1 and $58 \mathrm{kDa}$ endoplasmic reticulum protein (ERp58), have been reported after desflurane anesthesia (30). The presence of these antibodies suggests the induction of heterogeneous immune complexes following desflurane exposure.

\subsubsection{Sevoflurane}

Sevoflurane, the newest form of halogenated anesthetics, became available in 1995. Sevoflurane has many desirable clinical properties, including a nonpungent odor and low solubility in blood, which provides rapid induction and recovery. Studies have indicated that its administration is not associated with elevated ALT and AST levels (29). In contrast with older halogenated anesthetics, sevoflurane metabolism has not resulted in the formation of TFA; hence, hepatotoxic potential of sevoflurane is considered to be low $(36,37)$. A unique compound of sevoflurane metabolism, hexafluoroisopropanol (HFIP) has significantly less protein binding capability than TFA. In addition, HFIP does not accumulate and rapidly undergoes phase II biotransformation, specifically gluc- uronidation, to form HFIP-glucuronide. This compound is mostly excreted in the urine within 12 hours after anesthesia and is not detectable beyond 2 days (38-40). This is in contrast to previous anesthetics, where TFA is detectable in urine for up to 12 days after 75 minutes of anesthesia (41-43). However, sevoflurane has a low hepatotoxic potential as described in the current available literature $(8,44,45)$. As apparently, sevoflurane is unlikely to cause severe postoperative hepatic injury and is an ideal anesthetic for patients with previous exposure to other halogenated anesthetics or hepatic disease (46-48). Sevoflurane seems to be the best anesthetic choice in large size surgeries and liver transplants, intervention in which postoperative liver dysfunction could have harmful effects on patients. Interestingly, new studies demonstrated that sevoflurane pretreatment even exerts a protective effect on hepatic ischemia/reperfusion injury, which is a common problem in hepatic surgery $(47,49,50)$.

\subsection{Differential Diagnosis}

Reversible minor changes in liver function, immediately after anesthesia and operation occur frequently. Anesthesia-induce hepatotoxicity is a diagnosis of exclusion, so that ruling out other causes is essential. Clinical features similar to anesthesia-induced liver injury can be caused by acute viral hepatitis, exacerbation of previous chronic liver disease, hemolysis after blood transfusion, liver damage due to hypoxia (caused by vasoconstriction, shock, hypoxia, cardiac arrest ischemia), hypotension or liver damage due to other hepatotoxic drugs (antibiotics, antidepressants, phenothiazines, phenytoin, anticoagulants). For instance, from a histopathological point of view, centrolobular necrosis with mild cholestasis and fatty infiltration are associated with both hepatic necrosis due to halothane and hepatic necrosis caused by viruses. Therefore, sometimes it is impossible to distinguish them from each other. Furthermore, an operation per se may cause changes in liver function regardless of the type of anesthesia. Using anamnestic or serological tests together with clinical and epidemiological criteria would be helpful to distinguish anesthesia-induced hepatitis from other causes of hepatitis. Features of anesthesia-induced hepatitis include high fever onset day 3 to 14 , incidence of jaundice 1-2 days after fever, presence of no viral antibodies, latent period less than 15 days, recent exposure in $80 \%$ of cases, leukocytosis with eosinophilia (20\% following halothane but rare in viral hepatitis), fulminant course (40\% mortality vs. $1 \%$ for viral) and two times higher incidence in females.

\section{Conclusions}

Halogenated anesthesia-induced liver injury has been well documented in available literature. Beginning with halothane in the 1950s, halogenated anesthetics replaced the routine use of ether and chloroform. However, postoperative liver injury was soon recognized, es- 
pecially in patients re-exposed to halothane. Hepatitis followed by halothane anesthesia has high morbidity and mortality rates and survived patients may require a liver transplantation. Next generation of halogenated anesthetics including enflurane, isoflurane, desflurane, and sevoflurane have different molecular structures and are associated with less hepatotoxicity; however, rare instances of acute liver injury have been reported with all of these agents. The pattern of liver injury described with the newer halogenated anesthetics (enflurane, isoflurane and desflurane) has resembled that of halothane mechanism and evidence of autoimmune response to trifluoroacetylated liver proteins has been identified in patients' serum. A history of anesthesia-induced hepatitis is a reason to avoid subsequent exposure to halothane or other halogenated anesthetics, since crossed immunity can rarely occur. Unlike other halogenated anesthetics, sevoflurane is not metabolized to hepatotoxic trifluoroacetylated proteins; however, very few reports have described liver injury after sevoflurane exposure. In spite of the fact that anesthesia-induced liver injury is not a common occurrence, we should be aware of the association between the disease and the use of halogenated anesthetics.

\section{Authors' Contributions}

Conception and design, collection of data and writing of the manuscript: Saeid Safari; Conception and design, and data interpretation: Mahsa Motavaf and Seyed Alireza Seyed Siamdoust; Conception and design, and critical revision of the manuscript: Seyed Moayed Alavian.

\section{Financial Disclosure}

We declared no conflict of interest with any financial organization regarding the material discussed in the manuscript.

\section{References}

1. Zimmerman HJ. Hepatotoxicity: the adverse effects of drugs and other chemicals on the liver: Lippincott Williams and Wilkins; 1999.

2. Weber LW, Boll M, Stampfl A. Hepatotoxicity and mechanism of action of haloalkanes: carbon tetrachloride as a toxicological model. Crit Rev Toxicol. 2003;33(2):105-36.

3. Sinha A, Clatch RJ, Stuck G, Blumenthal SA, Patel SA. Isoflurane hepatotoxicity: a case report and review of the literature. Am J Gastroenterol. 1996;91(11):2406-9.

4. Singhal S, Gray T, Guzman G, Verma A, Anand K. Sevoflurane hepatotoxicity: a case report of sevoflurane hepatic necrosis and review of the literature. Am JTher. 2010;17(2):219-22.

5. Fee JP, Thompson GH. Comparative tolerability profiles of the inhaled anaesthetics. Drug Saf. 1997;16(3):157-70.

6. National Research Council (U.S.) Subcommittee on the National Halothane Study. The national halothane study: a study of the possible association between halothane anesthesia and postoperative hepatic necrosis; report: National Academies; 1969.

7. Mahboobi N, Esmaeili S, Safari S, Habibollahi P, Dabbagh A, Alavian SM. Halothane: how should it be used in a developing country? East Mediterr Health J. 2012;18(2):159-64.

8. Dabbagh A, Rajaei S. The role of anesthetic drugs in liver apoptosis. Hepat Mon. 2013;13(8)
9. Wright R, Eade OE, Chisholm M, Hawksley M, Lloyd B, Moles TM, et al. Controlled prospective study of the effect on liver function of multiple exposures to halothane. Lancet.1975;1(7911):817-20.

10. Pandit A, Sachdeva T, Bafna P. Drug-induced hepatotoxicity: A review. J Appl Pharm Sc. 2012;2(5).

11. Dabbagh A, Rajaei S. Halothane: Is there still any place for using the gas as an anesthetic? Hepat Mon. 2011;11(7):511-2.

12. Mushin WW, Rosen M, Jones EV. Post-halothane jaundice in relation to previous administration of halothane. $\mathrm{Br}$ Med $\mathrm{J}$. 1971;3(5765):18-22.

13. Inman WH, Mushin WW. Jaundice after repeated exposure to halothane: a further analysis of reports to the Committee on Safety of Medicines. BrMed J.1978;2(6150):1455-6.

14. Moult PJ, Sherlock S. Halothane-related hepatitis. A clinical study of twenty-six cases. QJ Med.1975;44(173):99-114.

15. Habibollahi P, Mahboobi N, Esmaeili S, Safari S, Dabbagh A, Alavian SM. Halothane-induced hepatitis: A forgotten issue in developing countries: Halothane-induced hepatitis. Hepat Mon. 2011;11(1):3-6.

16. Gut J, Christen U, Huwyler J. Mechanisms of halothane toxicity: novel insights. Pharmacol Ther.1993;58(2):133-55.

17. Dienstag JL. Halothans hepatitis: allergy or idiosyncrasy? N EnglJ Med.1980;303(2):102-4.

18. Kenna JG, Satoh H, Christ DD, Pohl LR. Metabolic basis for a drug hypersensitivity: antibodies in sera from patients with halothane hepatitis recognize liver neoantigens that contain the trifluoroacetyl group derived from halothane.J Pharmacol Exp Ther. 1988;245(3):1103-9.

19. Reichle FM, Conzen PF. Halogenated inhalational anaesthetics. Best Pract Res Clin Anaesthesiol. 2003;17(1):29-46.

20. Neuberger JM. Halothane and hepatitis. Incidence, predisposing factors and exposure guidelines. Drug Saf.1990;5(1):28-38.

21. Cousins MJ, Plummer JL, Hall PD. Risk factors for halothane hepatitis. Aust N Z J Surg. 1989;59(1):5-14.

22. Stoelting RK, Hillier SC. Pharmacology and physiology in anesthetic practice: Lippincott Williams and Wilkins; 2012.

23. Fuhrmann V, Jager B, Zubkova A, Drolz A. Hypoxic hepatitis epidemiology, pathophysiology and clinical management. Wien Klin Wochenschr. 2010;122(5-6):129-39.

24. Haseli N, Hassanzadeh J, Dehghani SM, Bahador A, Malek Hossei ni SA. Long-term survival and its related factors in pediatric liver transplant recipients of shiraz transplant center, shiraz, iran in 2012. Hepat Mon. 2013;13(7): e10257.

25. Lewis JH, Zimmerman HJ, Ishak KG, Mullick FG. Enflurane hepatotoxicity. A clinicopathologic study of 24 cases. Ann Intern Med. 1983;98(6):984-92.

26. Njoku D, Laster MJ, Gong DH, Eger EI, Reed GF, Martin JL. Biotrans formation of halothane, enflurane, isoflurane, and desflurane to trifluoroacetylated liver proteins: association between protein acylation and hepatic injury. Anesth Analg . 1997;84(1):173-8.

27. Khajavi M, Emami A, Etezadi F, Safari S, Sharifi A, Shariat Moharari R. Conscious Sedation and Analgesia in Colonoscopy: Ketamine/ Propofol Combination has Superior Patient Satisfaction Versus Fentanyl/Propofol. Anesth Pain Med. 2013;3(1):208-13.

28. Weitz J, Kienle P, Bohrer H, Hofmann W, Theilmann L, Otto G. Fatal hepatic necrosis after isoflurane anaesthesia. Anaesthesia. 1997;52(9):892-5

29. Ihtiyar E, Algin C, Haciolu A, Isiksoy S. Fatal isoflurane hepatotoxicity without re-exposure. Indian J Gastroenterol. 2006; 25(1):41-2.

30. Anderson JS, Rose NR, Martin JL, Eger EI, Njoku DB. Desflurane hepatitis associated with hapten and autoantigen-specific IgG4 antibodies. Anesth Analg. 2007;104(6):1452-3.

31. Katz J, Magee J, Baker B, Eger EI, 2nd. Hepatic necrosis associated with herpesvirus after anesthesia with desflurane and nitrous oxide. Anesth Analg. 1994;78(6):1173-6.

32. Tung D, Yoshida EM, Wang CS, Steinbrecher UP. Severe desflurane hepatotoxicity after colon surgery in an elderly patient. Can JAnaesth. 2005;52(2):133-6.

33. Berghaus TM, Baron A, Geier A, Lamerz R, Paumgartner G. Hepatotoxicity following desflurane anesthesia. Hepatology. 1999;29(2):613-4.

34. Eydi M, Golzari SE, Aghamohammadi D, Kolahdouzan K, Safari S, 
Ostadi Z. Postoperative Management of Shivering: A Comparison of Pethidine vs. Ketamine. Anesth Pain Med. 2014;4(2).

35. Hajiesmaeili MR, Motavaf M, Safari S. Regional analgesia in intensive care unit. Anesth Pain Med. 2013;3(2):263-5.

36. Bito H, Ikeda K. Renal and hepatic function in surgical patients after low-flow sevoflurane or isoflurane anesthesia. Anesth Analg. 1996;82(1):173-6.

37. Frink EJ Jr. The hepatic effects of sevoflurane. Anesth Analg. 1995;81( 6 Suppl):S46-50.

38. Kharasch ED, Karol MD, Lanni C, Sawchuk R. Clinical sevoflurane metabolism and disposition. I. Sevoflurane and metabolite pharmacokinetics. Anesthesiology. 1995;82(6):1369-78.

39. Ni J, Sato N, Fujii K, Yuge O. Urinary excretion of hexafluoroisopropanol glucuronide and fluoride in patients after sevoflurane anaesthesia. JPharm Pharmacol.1993;45(1):67-9.

40. Clavien PA, Selzner M, Rudiger HA, Graf R, Kadry Z, Rousson V, et al. A prospective randomized study in 100 consecutive patients undergoing major liver resection with versus without ischemic preconditioning. Ann Surg. 2003;238(6):843-50.

41. Rehder K, Forbes J, Alter H, Hessler O, Stier A. Halothane biotransformation in man: a quantitative study. Anesthesiology. 1967;28(4):711-5.

42. Movasseghi G, Hassani V, Mohaghegh MR, Safaeian R, Safari S, Zamani MM, et al. Comparison between spinal and general anesthesia in percutaneous nephrolithotomy. Anesth Pain Med. 2014;4(1).

43. Pouraghaei M, Moharamzadeh P, Soleimanpour H, Rahmani F,
Safari S, Mahmoodpoor A, et al. Comparison between the effects of alfentanil, fentanyl and sufentanil on hemodynamic indices during rapid sequence intubation in the emergency department. Anesth Pain Med. 2014;4(1)

44. Watanabe K, Hatakenaka S, Ikemune K, Chigyo Y, Kubozono T, Arai T. [A case of suspected liver dysfunction induced by sevoflurane anesthesia]. Masui.1993;42(6):902-5.

45. Eger EI, 2nd, Koblin DD, Bowland T, Ionescu P, Laster MJ, Fang Z, et al. Nephrotoxicity of sevoflurane versus desflurane anesthesia in volunteers. Anesth Analg. 1997;84(1):160-8.

46. Rahimzadeh P, Safari S, Faiz SH, Alavian SM. Anesthesia for patients with liver disease. Hepat Mon. 2014;14(7): e19881.

47. Mohseni M, Safari S, Alavian SM. Volatile anesthetics in ischemic liver injury: enemy or friend? Hepat Mon. 2014;14(6):e 19880.

48. Hassani V, Movassaghi G, Goodarzi V, Safari S. Comparison of fentanyl and fentanyl plus lidocaine on attenuation of hemodynamic responses to tracheal intubation in controlled hypertensive patients undergoing general anesthesia. Anesth Pain Med. 2013;2(3):115-8.

49. Bedirli N, Ofluoglu E, Kerem M, Utebey G, Alper M, Yilmazer $D$, et al. Hepatic energy metabolism and the differential protective effects of sevoflurane and isoflurane anesthesia in a rat hepatic ischemia-reperfusion injury model. Anesth Analg. 2008;106(3):830-7.

50. Zhou SP, Jiang P, Liu L, Liu H. Protective effect of sevoflurane on hepatic ischaemia/reperfusion injury in the rat: A dose-response study. EurJ Anaesthesiol. 2013. 